\title{
DETECTION OF RADIATION CONTAMINATION OBTAINED BY THE DEPLETED URANIUM AMMUNITION IN FIELD CONDITIONS
}

\author{
Mladen D. Nikolić, dipl. Ing. College for chemical-technological school, Kruševac, Serbia \\ mladennikolic2603@yahoo.com \\ MSc Fortuna Dragutin College for chemical-technological school, Kruševac, Serbia \\ PhD Dragan M. Nikolić, prof. College for chemical-technological school, Kruševac, Serbia \\ dragannikolic60@yahoo.com
}

\begin{abstract}
The paper discusses the characteristics of transmission imaging DECT who are most commonly used to detect radioactive contamination caused by the application of depleted uranium (DU), $30 \mathrm{~mm}$, under field conditions, during and after the NATO bombing. In a separate section of the paper discusses the Protection of beta emitting nuclei of DU projectiles.

Key words: depleted uranium, a portable X-ray detector, detection of radioactive contamination, beta radiation
\end{abstract}

\section{Introduction}

During the air strikes on the territory of the Federal Republic of Yugoslavia (FRY), NATO in 1999. he used ammunition with projectiles $(30 \mathrm{~mm})$ from the OU. Characteristics of the resulting radioactive contamination have been described in the literature $[1,2,3]$.
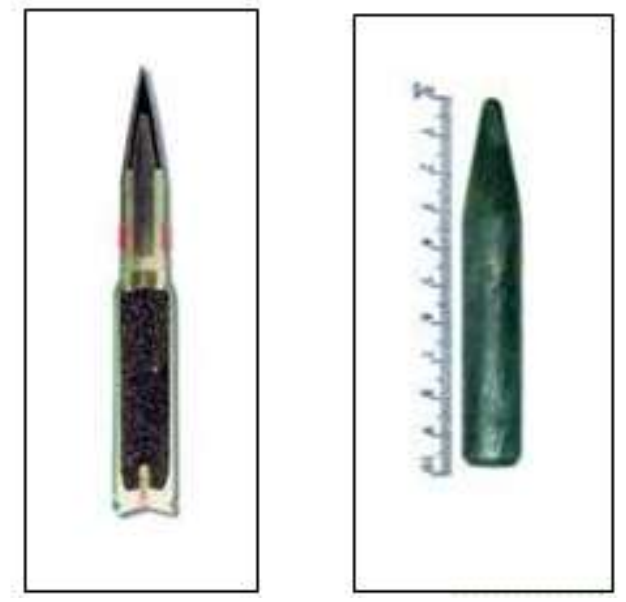

Figure $1.30 \mathrm{~mm}$ caliber bullet and core from the OU

The core of the projectile $(30 \mathrm{~mm})$ from the OU, emits alpha, beta, gamma and neutron radiation. Strength equivalent dose of gamma radiation at $5 \mathrm{~cm}$ from the projectile nucleus is approximately $2.7 \mu \mathrm{Sv} /$ ha to $1 \mathrm{~m}$ less than 0.1 $\mu \mathrm{Sv} / \mathrm{h}[4,5]$. Theoretical maximum equivalent dose of gamma irradiation of the whole body is $25 \mu \mathrm{Sv}$ for $1 \mathrm{~h}$ [6]. Neutron radiation is within the limits of variation of natural background neutron. Surface velocity emission of alpha particles, the surface of the projectile nucleus of $1 \mathrm{~cm} 2$, is 23 to 27 1s alpha particles in a volume calculated equivalent doses of alpha radiation (in direct contact with the core of the missile) is 0.4 to 0.5 $\mathrm{Sv} /(\mathrm{h} \cdot \mathrm{cm} 2)$ [7]. Surface velocity emission of beta particles from the surface of the projectile nucleus of $1 \mathrm{~cm} 2$, were 841 1s beta particles in a volume calculated equivalent doses of beta radiation (in direct contact with the core of the missile) is $1.4 \mathrm{mSv} /(\mathrm{h} \cdot \mathrm{cm} 2)$ [7] . OU is in the open field through efficiently detect beta radiation emitted $[4,5,8,9]$.

$\mathrm{OU}$ is a mixture of isotopes, including a strong emitter of beta radiation $234 \mathrm{mPa}$ (Emax. $=$ $2.3 \mathrm{MeV}$ ), which is in radioactive equilibrium with 238U. 238U is represented in percentage with $99.8 \%$. In practice, the control of radioactive contamination of DU is reduced to running, suitably protected beta probe, via contaminated surfaces, the $(1-3) \mathrm{cm}$. The probe is protected from contamination by thin nylon film. Depending on the thickness of the foil used beta radiation detection efficiency decreases to about $(5-20) \%$. Speed control adjusts inercionoj constants instrument. Counting Speed is compared with the response of the surface activity of $90 \mathrm{Sr}-90 \mathrm{Y}$ (or thin-source uranium). Response to surface activity is determined experimentally for each particular type of beta probe, before using them. Under field conditions, the soil cover and aerosol penetration into the deeper layers of the OU land, protected beta counting speed probes on the contaminated soil is 
compared with the speed of counting the beta particles uncontaminated soil (about 100 yards outside the area affected by DU projectiles). A suitable place to perform a more detailed expertise, including response to surface activity and taking soil samples for laboratory analysis. The counting rates of beta probes at a distance of $1 \mathrm{~cm}$, gamma photons involved with (5-7)\%. Control of radioactive contamination is performed with the use of appropriate protective equipment. Radioactive contamination from DU, beyond the sensitivity limits of the beta probe is determined by taking soil samples and their analysis by mass spectrometry, alpha spectrometry and gamma spectrometry.

In addition to uranium isotopes (238U, 235U, 234U) projectile nucleus contains trace $236 \mathrm{U}, 237 \mathrm{~Np}$ and $\mathrm{Pu} 239.240$ indicating that the missiles used to produce uranium waste from the processing of spent nuclear fuel [10].

Upon detection of radioactive contamination from the use of DU ammunition was used a number of instruments of domestic and foreign production. This paper describes the radiological detectors that are used in the most radioactively contaminated sites [1].

Figure 2 Set MRK-M.87
1. MRK M.87
2. Power adapter from the vehicle
4. Sarrying Case
5. Plastic bags for protection against contamination

2. Radioactive contamination meter M87 (MRKM87)

Layout set for MRK-M.87 has been shown in Figure 2.

MRK-M.87 is a handheld device designed for dosimetry in determining the amount of radioactive contamination of people, water, food, weapons, equipment, facilities and vehicles contaminated with radioactive fission products. The degree of radioactive contamination, as well as the DR-M.3, is determined by the gamma method. Unit reliably detects radioactivity missiles and missile components $(30 \mathrm{~mm})$, specific radioactivity of the soil with high levels of radioactive contamination (so-called "hot spots") and radioactivity holes penetrating missiles on combat and non-combat vehicles. Because of the low detection sensor surface, inadequate measurement units, unadjusted for ergonomic control surface contamination and a long response time, MRK-M.87 can not be used for a detailed radiological control soil contaminated with DU and performance testing carried out decontamination work in the field. MRK-M.87 can be used on contaminated sites to measure the natural background gamma radiation.

\section{Modified universal monitor radiation KOMO-} $\mathrm{TN}$

The appearance of the universal sets modified radiation monitor KOMO-TN is shown in Figure 3. 


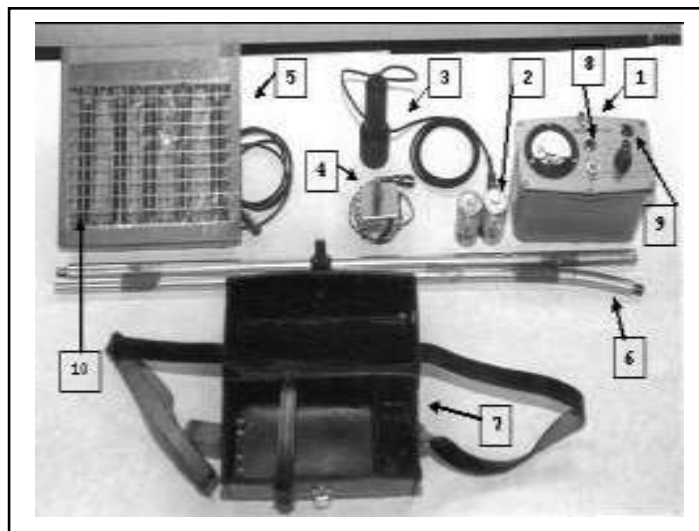

Figure 3. The set of modified universal detector

1. detector, 2. sources of supply, 3. Standard probe(GM tube ZP 1451), 4. speaker cable and connector,5. new detection probe with $5 \mathrm{gm}$ tubes, 6 . aluminum holders detection probes, 7. leather case with strap for detector carrying, 8 speaker connector, 9 connection detection probes, 10 LCT 3B17 GM tube

Universal monitor radiation $\mathrm{KOMO}-\mathrm{TN}$ is an integral part of the transmission sets of radiometric laboratories LARA-2. The basic version is a device intended to measure the radiation fields of gamma radiation, beta activity measurements of samples contaminated with fission products, determination of the degree of contamination of various surfaces and assessment of alpha contamination. Modification, with the added and modified parts (4, 5, 6 and 8 in Fig. 3), obtained significantly improved device characteristics. Due to the satisfactory sensitivity for surface contamination and the possibility of beta emitters alternating use of standard probes and new probes (large detection area), the modified universal monitor radiation KOMO-TN can be used to control radiological contamination of land with DU and performance testing carried out decontamination work in the field.

\section{Universal radiation monitor KOMO-TM}

The appearance of the universal radiation monitor KOMO-TM is shown in Figure 4.

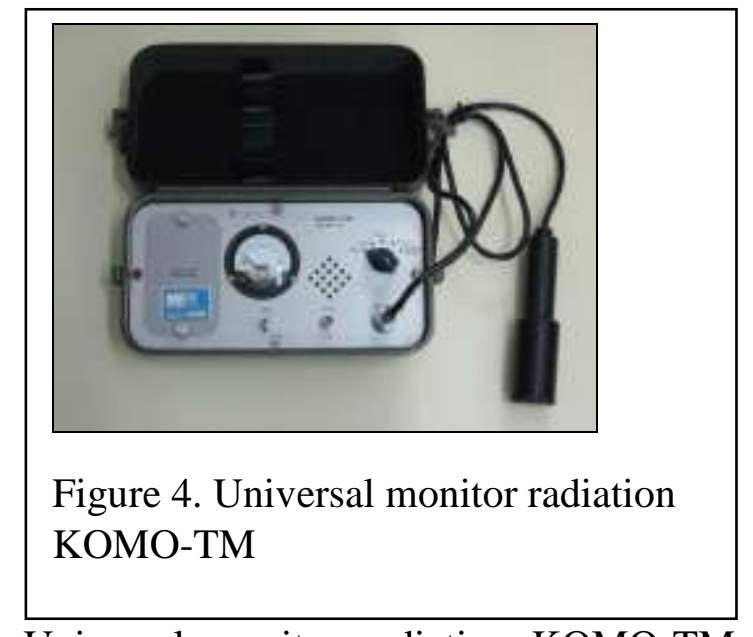

Universal monitor radiation KOMO-TM is an integral part of the pack radiometric laboratories M.2 (LR-M.2) and LARA-10. The device is designed to measure the radiation fields of gamma radiation, beta activity measurements of samples contaminated with fission products and the determination of the degree of radioactive contamination of various surfaces. When working in the field conditions, the device needs to be done to improvise or carry strap and handle the probe. The installation was done additional probe, large detection area $(90 \mathrm{~cm} 2), 3 \mathrm{gm}$ tubes (the same as the type of KOMO-TN). Due to the satisfactory sensitivity for beta radiation and the possibility of using a standard AC probes and additional probes (large detection area), the universal radiation monitor KOMO-TM can be used to control radiological contamination of land with DU and performance testing carried out decontamination work in the field.

\section{Contamination monitor ADK 6150}

The contamination monitor ADK 6150 is shown in Figure 5. 


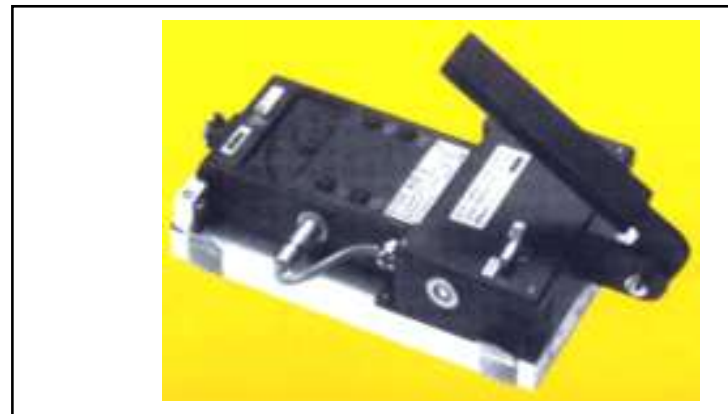

Figure 5. Contamination monitor ADK 6150

Monitor contamination ADK 6150 (Fig.

5) is structurally solved so that I fit the meter mounted on top, "useless" proportional surface probe with handle. Guardrail may be extended with additional aluminum handle, sets the monitor contamination. The meter is available in more variants (6150 AD1, AD2 6150, 6150 AD3, AD4 6150, 6150 and 6150 AD5 AD6) and a central unit to which, according to the characteristics of the meter, I can connect the appropriate detection probes with different characteristics. There are variants to the correct type of meter is set to other types of stationary or portable devices (alarm station, teletektor et al.), Then making them one functional unit. When using the monitor contamination can be easily and functionally protected from radioactive contamination. The device is used in INN "Vinca" to perform specific tasks of the institute. Because of the very high sensitivity for beta radiation, excellent sound indications, good ergonomics, high reliability and large detection area of the probe, contamination monitor 6150 ADK can be used to control radiological contamination of land with DU and performance testing carried out decontamination work in the field. For contamination control can be used and the combination meter 6150 AD6 with alphabeta-gamma probe $6150 \mathrm{AD}-17$. This probe has similar characteristics as the measurement standard universal probe radiation monitor KOMO-TN.

\section{Universal monitor LB 123 (Umo LB 123) with a probe LB 1231}

Apperance of Umo LB 123 with probe LB 1231 is shown in figure 6 .

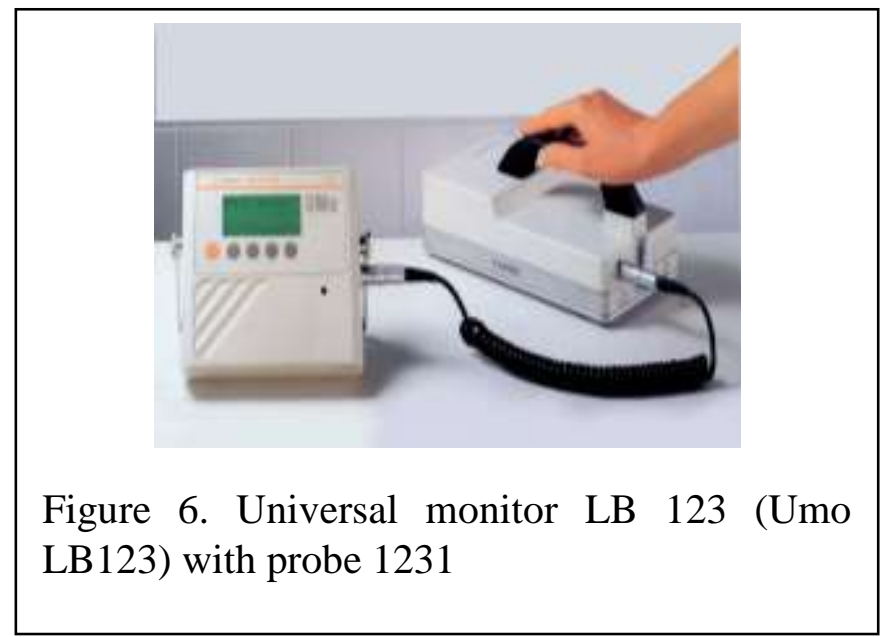

Umo LB 123 with a probe LB 1231 is a contemporary, portable proportional counter. In memory stored data on the calibration factors of surface activity for 25 radionuclides that are in practice often occur as contaminants. This device has a high sensitivity for beta radiation and very good sound indication. It is possible (in soil density of $1.24 \mathrm{~g} / \mathrm{cm} 3)$ detect missile $(30 \mathrm{~mm})$ from OU to a depth of $26 \mathrm{~cm}$ [2]. With Figure 8 Umo see that LB 123 LB 1231 A probe is not suitable for continuous measurement of surface radioactive contamination of large areas of land. It was used at Cape Arza to verify the existence of radioactive contamination $\mathrm{OU}$ in that place, which is detected by other instruments and performance testing carried out decontamination [2].

\section{Beta radiation of the core of depleted uranium projectiles}

The largest contribution to the dose from external radiation from the nucleus of DU projectiles in its immediate vicinity, gives beta radiation [21]. Most commonly, the classic radiation protection pays attention to gamma radiation in this case, at a distance of $1 \mathrm{~cm}$, represents only $7 \%$ of the total dose from external radiation. Therefore, in one laboratory exercises, in order to optimize radiation protection, and the measured beta radiation radioactive nuclei of DU projectiles $(30 \mathrm{~mm})$, which was placed in a Plexiglas box ( $5 \mathrm{~mm}$ thick). Measuring method is shown in Figure 7. 


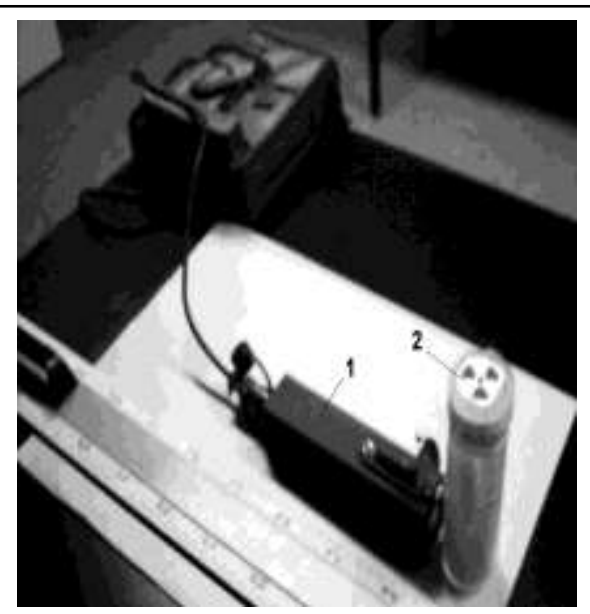

Figure 7 Measuring the intensity of the absorbed dose of beta radiation

1. beta / gamma probe AN/PDR-77

2. nucleus of DU projectiles in a plexiglass box

Was used for the measurement of multifunctional imaging detector AN/PDR-77 [22]. Beta / gamma probe AN/PDR-77, with an open window as shown in Figure 9, the measured beta radiation absorbed dose of $0.1 \mu \mathrm{Gy} / \mathrm{h}$ to 5 cGy / h. Data on the absorbed dose of beta radiation in the air, at different distances from the nucleus of DU projectiles, obtained by the Monte Carlo method, taken from literature [21]. The calculated and measured values of the absorbed dose intensity of beta radiation are shown in Table 1.

The results on the strength of the absorbed dose of beta radiation in air, obtained by Monte Carlo, (dD / dt) MC, corrected cumulative attenuation coefficients for Plexiglas and air layer, $\mathrm{X}$, and is obtained by calculating the value of the absorbed dose of beta radiation in the air, after the passage of different type of absorber, $(\mathrm{dD} / \mathrm{dt}) \mathrm{x}$. Measured values of the absorbed dose of beta radiation in the air marked with $(\mathrm{dD} / \mathrm{dt})$ m. Measurements were carried out in an automatic forfeiture regime phon. The measurement results were analyzed using the Statistical EduStat 4.05. Attenuation coefficient was calculated by the formula [23]:

$$
K_{\mathrm{S}}=\mathrm{e}^{-[\mu(\beta, \mathrm{p}) \cdot \rho(\mathrm{p}) \cdot \mathrm{x}(\mathrm{p})]} \cdot \mathrm{e}^{-[\mu(\beta, \mathrm{v}) \cdot \rho(\mathrm{v}) \cdot \mathrm{x}(\mathrm{v})]}
$$

where are;

- $\mu(\beta, p)$ - ratio of mass energy absorption of beta radiation in plexiglass $(\mathrm{cm} 2 / \mathrm{g})$,

- $\rho(\mathrm{p})$ - Plexiglas density $(1.18 \mathrm{~g} / \mathrm{cm} 3)$,

- $x(p)$ - the thickness of Plexiglas $(\mathrm{cm})$

- $\mu(\beta, v)$ - ratio of mass energy absorption of beta radiation in air $(\mathrm{cm} 2 / \mathrm{g})$, $\mathrm{g} / \mathrm{cm} 3)$ and

- $\rho(p)$ - the density of air $(0.001293$

- $x(p)$ - air layer thickness (cm).

Mass energy absorption coefficients of beta radiation, plexiglass and air, were calculated by the formula [23]:

$$
\mu(\beta, p)=17\left(E_{\max }\right)^{-1,14}\left(\mathrm{~cm}^{2} / \mathrm{g}\right) \text { i } \mu(\beta, \mathrm{v})=
$$
$16\left(E_{\max }-0,036\right)^{-1,4}\left(\mathrm{~cm}^{2} / \mathrm{g}\right)$.

Emax is taken for the value of $2.3 \mathrm{MeV}$.

Table 1. Calculated and the measured values of the absorbed dose of beta radiation from the surface of the core of DU projectiles (in a

\begin{tabular}{|c|c|c|c|c|}
\hline DISTANC & & & & \\
\hline E FROM & & & $(\mathrm{d} D / \mathrm{d} t)$ & \\
\hline CORE & $(\mathrm{d} D / \mathrm{d} t)$ & & & \\
\hline SURFACE & & $K_{\mathrm{s}}$ & $\stackrel{x}{(u G v / h}$ & $(u \mathrm{Gv} / \mathrm{h})$ \\
\hline $\begin{array}{l}\text { MISSILE } \\
(\mathrm{cm})\end{array}$ & $(\mu \mathrm{Gy} / \mathrm{h})$ & & & \\
\hline 0 & 1960 & - & 1960 & - \\
\hline & & 0,02 & & $2,349 \pm$ \\
\hline 5 & 144 & 06 & 2,97 & 0,042 \\
\hline 1 & & 0,02 & & $11,088 \pm$ \\
\hline 10 & 40 & 13 &, 98 & 0,092 \\
\hline
\end{tabular}
plexiglass box)

Note:

At a distance of $1 \mathrm{~cm}$ was measured absorbed dose of beta radiation of about 6 $\mu \mathrm{Gy} / \mathrm{h}$ but due to lack of proper values in the literature [21], obtained by Monte Carlo, was not included in the table.

The results of calculations and measurements indicate the importance and necessity of taking proper care of beta radiation when working with projektilia from OU, regardless of whether they are carrying out rehabilitation works and laboratory exercises.

Conclusion 
During the air strikes on the territory of the Federal Republic of Yugoslavia (FRY), NATO in 1999. he used ammunition with projectiles $(30 \mathrm{~mm})$ from the OU.

For the detection of radioactive contamination caused by the application of depleted uranium (DU), $30 \mathrm{~mm}$, under field conditions, during and after the NATO bombing kotišćeni the DECT portable imaging such as radioactive contamination meter M.87 (MRKM.87) , modified universal monitor radiation KOMO-TN, universal monitor radiation KOMOTM monitor contamination ADK 6150, universal monitor LB 123 (Umo LB 123) with a probe LB 1231 and others. Depleted uranium is in the open field through efficiently detect beta radiation emitted, and the test results indicate the importance of the need for protection against beta radiation when working with missiles based on OU.

\section{Reference}

[1] B. Djurovic et all, Depleted Uranium (detection methods, direct repair effects and prevent late consequences), Draslar Partner, Belgrade, 2011., pp. 31-36

[2] P. Vukotic, Anđelić T., Zeki R., M. Kovacevic, V. Vasic, N. Ristic, D. Fortune,

Dosimetric experience decontamination Arza from depleted uranium, XXI pp. 201-208

JDZZ Symposium Proceedings, Belgrade, 2001.,

[3] S. Petkovic, M. Zaric, Z. Devic, use of depleted uranium ammunition in

NATO aggression against the Federal Republic of Yugoslavia, Chemical Industry No2, Belgrade

2002nd, pp. 62-68

[4] UNEP, Depleted Uranium in Serbia and Montenegro, Post-Conflict Environmental

Assessment in the Federal Republic of Yugoslavia, Switzerland, 2002.

[5] UNEP, Depleted Uranium in Bosnia and Herzegovina, Post-Conflict Environmental Assessment, Switzerland, 2003.

[6] S. Fetter, Von Hippel F. N., The hazard posed by depleted uranium munitions, Sci. Global Security 8, 1999., Pp. 125-161

[7] D. Ristic, R. Benderać, Vejnović Z., M. Orlic, S. Pavlovic, ammunition used by
NATO forces in Bosnia made from depleted uranium, INN Newsletter

"Vinca" no. 4, 1997., Pp. 205-212

[8] D. Fortune, D. Dimitrijevic, Senic women., Practical aspects of the detection of radiation

contamination caused by the application of depleted uranium, chemical

Industry No2, Belgrade, 2002., pp. 98-100

[9] G. Pantelic, G. Kolarević, Z. Ivkovic, Dosimetric control shell PGU-14 / B

API penetrator of depleted uranium, XXI Symposium JDZZ, Proceedings

contractors, Beograd, 2001., pp. 375-378

[10] V. Bar, Radenkovic M., Paligorić D., Djuric, J., Alfaspektrometrijska analysis

missiles with depleted uranium, XXI Symposium

JDZZ, Proceedings

contractors, Beograd, 2001., pp. 69-72

[11] Radiological detector M.3 (DR-M.3), VIZ, Belgrade, 1978.

[12] The meter of radioactive contamination M87

(MRK-M87), VIZ, Belgrade, 1989.

[13] I. Dimitrijevic, S. Mihajlovic, Detection and dosimetry of radiation, VIZ,

Belgrade, 1982., Pp. 400-405

[14] Portable X-ray radiation meter KOMO-TN

Description with instructions for handling, IBK "Vinca", Belgrade, 1980.

[15] I. Dimitrijevic, S. Mihajlovic, Detection and dosimetry of radiation, VIZ, Belgrade, 1982., Pp. 374-392

[16] P. Markovic, Ristic DJ., Mirić I., P. Miric, Calibration of instruments for measuring Belgrade, 1964 surface contamination, IBK-93, IBK "Vinca",

[17] Philips data handbook, Electron tubes, Book T6, 1986., Pp. 97-100

[18] Radiological contamination meter KOMOTL, Description with instructions for handling, IBK "Vinca", Belgrade, 1985.

[19] Dose rate meter 5/6/k 6150 AD, Operating Manual, Automess GmbH, 1995.

[20] Operating Manual, UMO LB 123, Berthold Technologies, EGG Berthold, 1993.

[21] R. Pollanen et all, Characterisation of projectiles composed of depleted uranium,

Journal of Environmental Radioactivity 64 (2003), pp. $133-142$

[22] Radiac Set AN / PDR - 77, Technical Manual, New Jersey, 1995.

[23] J. Martin E. Physics for Radiation Protection, Second Edition, Strauss GmbH, Mörlenbach, 2006. 